\title{
A Comparison of Malaria Prevention Behaviors, Care-seeking Practices and Barriers Between Malaria at-risk Worksite Migrant Workers and Villagers in Northern Shan State, Myanmar - a Mixed Method Study
}

Ye Kyaw Aung ( $\nabla$ ykaung@psimyanmar.org )

Population Services International Myanmar https://orcid.org/0000-0001-7488-6412

Su Su Zin

Population Services International Myanmar

Kemi Tesfazghi

Population Services International

Mahesh Paudel

Population Services International

May Me Thet

Population Services International Myanmar

Si Thu Thein

Population Services International Myanmar

\section{Research Article}

Keywords: Migrant workers, Malaria Prevention behaviors, Care seeking Practices, Worksites, Myanmar

Posted Date: January 28th, 2022

DOI: https://doi.org/10.21203/rs.3.rs-1276731/v1

License: (c) (i) This work is licensed under a Creative Commons Attribution 4.0 International License.

Read Full License 


\section{Abstract}

Background: Migrant populations are at an increased risk of exposure to malaria due to their nature of work and seasonal migration. This study aimed to compare malaria prevention behaviors and care seeking practices among worksite migrant workers and villagers in the malaria-at-risk areas of the Eastern Myanmar close to the China border.

Method: A mixed method study was conducted in March 2019. The malaria-at-risk worksites in the targeted four townships, and villages located at the nearest to these worksites were approached. The key stakeholders, such as worksite managers and village leaders, were interviewed.

Results: A total of 23 worksites, which employed 880 migrants and 447 locals, and 20 villages, which were homes for 621 migrants and 9731 locals, were successfully interviewed. Regarding malaria prevention behaviors, sleeping under bed net was common among both worksites (74\%) and villages (85\%). In contrast, insecticide treated nets/long-lasting-insecticidal-nets (ITN/LLIN) usage was much lower among the worksites than villages (39\% vs $80 \%$ ). Regarding care seeking practices for febrile illness, self-medication was a popular choice for both worksite workers and villagers owing to easy availability of western medicine. Moreover, local-belief-driven traditional practices were more common among villagers. On occasions when fever was not relieved, both would seek health care from rural health centers, private clinics, or public hospital. As for barriers, villagers mostly cited language barriers, which often led to misunderstanding between health providers and them. In contrast, most of the worksites cited logistic issues as they were in remote areas with devastated road conditions and the routes to formal health facilities were not secure due to frequent armed conflicts.

Conclusion: This study demonstrated that site-workers and villagers had different malaria prevention behaviors and care seeking practices even though they resided in the same geographic area. Hence, it is important to recognize such differences for more effective intervention approaches.

\section{Introduction}

Globally, malaria morbidity and mortality declined between 2010 and 2016 (1). However, it is still one of the important public health issues in the Greater Mekong Subregion (GMS) including Myanmar, Cambodia, the Lao People's Democratic Republic, Thailand, Vietnam, and Yunnan Province of the People's Republic of China with the emergence of a resistance to artemisinin-based combination therapy (2). Among GMS countries, Myanmar bore the heaviest malaria burden in 2016 (3) in spite of malaria case reduction by $82 \%$ and death reduction by $93 \%$ between 2012 and 2017 (4). Within Myanmar, northern regions near China experienced high malaria burden and frequent outbreaks (5).

Regarding the risk factors of malaria, there are forest-related activities, difficulty in implementing and strengthening control interventions, remoteness, presence of the exophagic and exophilic vector, poor lifestyle, poor education standard, and low risk perception in the GMS countries (6). Among those risk factors, the study in Vietnam pointed out forest-related activities as an important factor with a population 
attributable fraction of 53\% (6). In Northern Myanmar along the border with China, which have been neglected for malaria control, the thickly forested geography, difficulty to access to infrastructure, sustained cross-border passing, and political conflict causes major barriers for malaria control, facilitating transmission to nearby regions (5). In addition, the lack of physical, monetary and human resources leads to malaria outbreak in these areas (5).

Due to the changing economy, the migrant worker population is rising in the GMS (7). The mobile and migrant workers are more likely to be exposed to malaria and act as a carrier of drug-resistant malaria (2). Their work nature and seasonal migration encourages the disease spread from endemic areas to malaria-free ones in the GMS (7). Despite the fall in morbidity and mortality in recent years, Myanmar has been experiencing burden of drug-resistant malaria especially in Thailand-Myanmar border more likely due to the population mobility (8). In Myanmar, as mobile migrant workers tend to move frequently, bringing along their families for their living and/or job availability, this prevents them from getting sufficient health information and accessing quality health services and increases their likelihood of receiving low-quality drug, delayed diagnosis, poor treatment and inadequate follow up (2). These factors hamper malaria elimination efforts and contribute to emergence of drug-resistant malaria (2).

Regarding the treatment-seeking behavior, the socio-economic factors, health knowledge, beliefs and access to health services influence patients' health seeking behavior (9). A study in Lao PDR and Cambodia showed that various socio-economic factors and/or culture and belief of the specific mobile group play a role in acceptance and compliance to antimalarial treatment (10). People begin doing selftreatment or receiving treatment from traditional healers and then, seek care from private drug sellers with few going to public facilities directly $(11,12)$. In a household survey in Cambodia, the percentage of people who sought healthcare from private providers was two-thirds (13).

In Myanmar, a considerably large number of populations seek treatment from private sector, including non-formal providers (14). A survey in Myanmar showed that almost $50 \%$ of people sought medical attention from private providers, who more likely administer anti-malarials without any diagnostic test (15). Moreover, the study in Wa township showed that approximately $80 \%$ of patients with febrile illness sought care from the retail sector (drug peddlers, shops and market stalls) (16).

Therefore, it is important to understand role of different health providers and engage with them appropriately to facilitate malaria elimination goals (9). The informal providers located in remote areas have a tendency to provide healthcare for poor and marginalized population (17). In addition, mobile and migrant populations are less likely to receive healthcare from formal health services (18). Although mobile and migrant populations encountered fewer barriers while getting treated by informal providers, the health service and treatment received was of sub-standard quality (7).

With funding from the Global Fund, Population Services International (PSI)/Myanmar planned to expand its community health service provider network through non-formal providers to be able to serve mobile and migrant population better in four high burden and conflict-affected townships (Hsipaw, Kutkai, Kyaukme and Lashio) in Nothern Shan state near the Myanmar-China border. Along the border, there were 
high malaria prevalence and weak malaria services in health facilities due to lack of experienced health workers and medical equipment (19). In addition, its geographical presentations of hilly and heavily occupied forest, increasing numbers of mobile and migrant occupants also favors malaria transmission (20-23). Prior to implementing PSI/Myanmar's project, this study was conducted to be able to learn malaria prevention behaviors and treatment seeking behaviors of villagers and mobile and migrant workers who resided in the same geographic area.

\section{Methods}

\section{Study design}

A mixed method approach was applied to explore the malaria preventive measures, health seeking behavior and barriers to access health care among mobile, migrant, and general populations working or residing in malaria-at-risk areas in four townships of Northern Shan-State (namely, Hsipaw, Kutkai, Kyaukme and Lashio). In this study, mobile is defined as those persons present in the study location for less than 6 months while migrant means persons who move between townships and are present in the study location for more than 6 months, but less than 12 months (24). "Ethnic minority" persons are those from ethnic minority groups as determined by 2014 Myanmar Housing and Population Census, which are not the 8 major national ethnic races (15). Prior to this study, we reviewed the list of worksites located at malaria-at-risk areas in these townships conducted by PSI Myanmar using a proper census approach during August and December 2016. This list included number of worksites and its worker size. Such worksites list was updated after conducting group work mapping exercise based on perceived knowledge of the basic health staff being assigned for the study areas. This exercise was conducted in the respective township medical office in early March 2019 with an aid of the Township medical officers and Township Vector Borne Disease Control team. Then, the worksites included in the list and the villages residing at the nearest of these listed worksites were approached, and one of the representatives each was interviewed using both a structured quantitative questionnaire and a qualitative interview guide. The quantitative structured questionnaire aimed to explore the size of mobile and migrant populations, their mobility and their malaria preventive measures in both worksites and villages. The qualitative questions explored health seeking behavior, provider preference, and barriers to health care among those populations.

\section{Study population}

The study population was the key stakeholders of these worksites, for instance, worksite managers or owners, were approached for interviews. Additionally, the nearest village of these worksites was identified, and each village leader or representative was asked for interviews. Finally, 23 worksites and 20 villages were approached for quantitative interviews. Of those approached worksites and villages, 14 qualitative interviews each were conducted. 


\section{Data collection}

The field data collection was conducted by PSI Myanmar research team in March 2019. Electronic data collection using the Census and Survey Processing System (CsPro) software version 7.1 was applied. The quantitative questionnaire included questions related to the basic information of businesses and villages and malaria preventive measures among those populations. For the qualitative in-depth interviews, PSI Myanmar research team prepared a draft interview guide, which mainly included the questions of health seeking practices for any febrile illness and malaria-suggestive symptoms. The question guide was subsequently improved after conducting pretest with the PSI's experienced researchers. The guide included prompts that elicit storytelling from interviewees, allowing participants to provide information at their own pace and using probes to elicit additional detail. The qualitative interviews were audio-recorded.

\section{Data analysis}

Quantitative data analysis was conducted in STATA 14.2 (@ StataCorp, College Station, TX) (25). The population size of mobile and migrant workers and villagers was calculated based on the responses to the separate questions on each group of mobile and migrant population working in the interviewed worksites or residing in the approached villages. Additionally, their common malaria preventive practices were explored and compared between the worksites and the nearby villages using Pearson Chi-squared test. A statistical test of $p$-value less than 0.05 was assumed to be significant.

For the qualitative data, the audio recordings were first transcribed into local language, Burmese. Then, transcripts were coded to all relevant statements or quotes and checked whether these codes give rise to patterns of information. A chart was designed to consolidate each code mentioned by an individual participant and verified by the analysis team. This procedure was carried out for each of the transcripts. Subsequently, the themes under the topics of treatment seeking practices and barriers were developed using a thematic approach in analyzing contents of interviews. Then, they were orderly reported by frequency of the topic. Atlas.ti software version 7.1.7 was applied for coding the data.

\section{Ethical considerations}

This study has been approved by the Ethics Review Committee on Medical Research Involving Human Subjects, Department of Medical Research, Ministry of Health and Sports, Myanmar (Ethics/DMR/2019/007) and the PSI Research Ethics Board (\#21.2018).

\section{Results}

\section{Population size estimates of general, mobile, and migrant people}

There were 1,327 workers employed in the approached 23 worksites with a median of 33 workers per worksite. Among those workers, approximately $34 \%$ were women with $2 \%$ of pregnant women and $7.9 \%$ 
were children aged under five. In the approached nearby 20 villages, there were 10,352 villagers with a median 424-villager size each. More than half of the people residing in the villages were female with $2.67 \%$ of pregnant women and $13.3 \%$ of the villages' population were under-five children.

Overall, higher number of mobile and migrant people resided in the worksites than in the nearby villages $(p<0.001)$. The representatives of 20 worksites reported that they had migrant workers moved to their workplace at any time since their birth whereas 12 village heads reported so. 14 out of 23 worksites had mobile population and 11 had migrants. Of the 20 interviewed villages, only 3 and 4 villages had mobile and migrant residents in their villages, respectively. In addition, the percentage of any mobile migrant population since their birth was higher in the approached worksites than in the approached villages (66.3\% vs. 6.0\%). The percentage of mobile population living in the study locations for less than 6 months was $13.0 \%$ in the worksites and $1.2 \%$ in the villages whereas the migrants residing in the study areas for more than 6 months, but less than 12 months made up of $21.3 \%$ workers for the worksites and $0.9 \%$ villagers for the villages.

\section{Characteristics of study participants and study areas}

A total of 43 participants comprising 23 worksite representatives and 20 village representatives took part in the quantitative study whereas 14 representatives participated in the qualitative in-depth interview. Most respondents were male for both sites with median age of 42 years for the worksite representatives and 49 years for the village representatives. All participants had at least primary school standard, and 8 worksite respondents graduated. Most businesses were found to be agriculture and mining for both worksites and villages nearby. Of those 23 approached worksites, 17 worksites located within the forest while 6 were within 5 miles from the forest. For 20 villages nearby, 12 villages stood within the forest while 6 and 2 villages were within 5 miles and more than 5 miles from the forest, respectively. 
Table 1

Population sizes of general, mobile and migrant people in the interviewed worksites and villages

\section{Defined indicators}

Worksites
Pvalue

\section{General Population}

Total number of worksites/ villages interviewed

23

20

Median number of workers/villagers (min - max)

$33(6-$

384)

$424(35-$ 2982)

Total number of workers/ villagers

1327

10352

$\%$ of female populations in the interviewed worksite/village

451

$(34.0 \%)$

5612

$(54.2 \%)$

$\%$ of pregnant women in the interviewed worksite/village

$9^{a}(2.0 \%)$

$150^{\mu}$

0.387

$(2.67 \%)$

$\%$ of under 5 children in the interviewed worksite/village

105

$(7.9 \%)$

1380

$(13.3 \%)$

$<0.001$

Mobile and Migrant Population

$\%$ of worksite/village with any mobile migrant population since their birth

$\%$ of any mobile migrant population since their birth in the approached worksite/village

$\%$ of mobile population ${ }^{1}$ in the approached worksite/village

$\%$ of migrants ${ }^{2}$ in the approached worksite/village

20

$(87.0 \%)$

880

$(66.3 \%)$

173

$(13.0 \%)$

283

$(21.3 \%)$
$12(60.0 \%)$

0.043

$621(6.0 \%) \quad<0.001$

124

$(1.20 \%)$

$93(0.90 \%) \quad<0.001$

${ }^{a} N=451,{ }^{\mu} N=5612$.

1"Mobile" are those persons present in the study location for less than 6 months.

2"Migrant" mean persons who move between townships and are present in the study location for more than 6 months but less than 12 months. 
Table 2

Characteristics of the study participants and study areas

\begin{tabular}{|c|c|c|c|}
\hline Variables & Category & $\begin{array}{l}\text { Worksites } \\
(\mathrm{N}=23)\end{array}$ & $\begin{array}{l}\text { Villages } \\
\text { nearby } \\
(\mathrm{N}=20)\end{array}$ \\
\hline \multirow[t]{2}{*}{ Gender } & Male & 20 & 18 \\
\hline & Female & 3 & 2 \\
\hline Age & Median (Min - Max) & $\begin{array}{l}42(25- \\
66)\end{array}$ & $\begin{array}{l}49(25- \\
67)\end{array}$ \\
\hline \multirow[t]{4}{*}{ Education } & Graduated & 8 & 1 \\
\hline & High school standard & 4 & 6 \\
\hline & Middle school standard & 8 & 7 \\
\hline & Primary school standard & 3 & 6 \\
\hline \multirow[t]{4}{*}{ Townships } & Hsipaw & 9 & 7 \\
\hline & Kutkai & 4 & 4 \\
\hline & Kyaukme & 6 & 5 \\
\hline & Lashio & 4 & 4 \\
\hline \multirow[t]{5}{*}{ Position at worksite or village } & Village leader & - & 14 \\
\hline & Village representatives & - & 6 \\
\hline & Owner & 5 & - \\
\hline & Manager/Supervisor & 14 & - \\
\hline & Worksite representatives & 4 & - \\
\hline \multirow{5}{*}{$\begin{array}{l}\text { Types of worksites/Current main } \\
\text { business of villages }\end{array}$} & Agriculture & 10 & 8 \\
\hline & Factory & 3 & 4 \\
\hline & Farming & 2 & 2 \\
\hline & Mining & 6 & 4 \\
\hline & Construction & 2 & 2 \\
\hline \multirow[t]{3}{*}{ Location of worksites/villages } & Within the forest & 17 & 12 \\
\hline & Within 5 miles from the forest & 6 & 6 \\
\hline & $>5$ miles from the forest & 0 & 2 \\
\hline Types of studies conducted & Only qualitative in-depth interviews & 14 & 14 \\
\hline
\end{tabular}




\begin{tabular}{|llll|}
\hline Variables & Category & $\begin{array}{l}\text { Worksites } \\
\mathbf{N}=\mathbf{2 3})\end{array}$ & $\begin{array}{l}\text { Villages } \\
\text { nearby } \\
\mathbf{( N = 2 0 )}\end{array}$ \\
\hline & $\begin{array}{l}\text { Both structured quantitative and } \\
\text { qualitative interviews }\end{array}$ & 23 & 20 \\
\hline
\end{tabular}

\section{Internal migrations into the study areas}

The worksite representatives and village heads reported that majority of migrants moved from the central regions of the country, mainly from Magway, Sagaing and Mandalay Divisions. In addition, some migrants working in Lashio worksites moved from Mrauk-U, Rakhine State, and intra-state migration was also noted in Hsipaw Township (Figure 1).

\section{Malaria preventive measures}

Regarding the questions on practices of malaria preventive measures, $73.9 \%$ of worksite managers and $85 \%$ of village heads responded that their workers or villagers usually slept under bed net whereas $39.1 \%$ of the worksites and $80 \%$ of the villages mentioned ITN/LLIN use ( $p=0.007)$. Secondly, $30.4 \%$ of the worksites and $65 \%$ of the villages respectively had a practice of burning incense or coil for a purpose of mitigating mosquito bites. Moreover, $8.7 \%$ of the worksites used to burn leaves aiming to eliminate mosquito reservoir and repelling mosquito while only $4.35 \%$ used insect repellents. For the villages, $30 \%$ of the respondents answered that they usually burnt leave whereas $15 \%$ applied insect repellents to mitigate mosquito bite. Moreover, $47.8 \%$ of the worksites and $75 \%$ of the villages responded positive to the exercise of their residents wearing protective clothing to prevent from mosquito bite. However, taking malaria prophylactic drugs was no longer a popular choice making up of only $4.35 \%$ for the worksites and $10 \%$ for the villages adopting such practice. 
Table 3

Malaria preventive measures

\begin{tabular}{|c|c|c|c|}
\hline Defined Indicators & $\begin{array}{l}\text { Worksites } \\
(\mathrm{N}=23)\end{array}$ & $\begin{array}{l}\text { Villages nearby } \\
(\mathrm{N}=20)\end{array}$ & P-value \\
\hline \multicolumn{4}{|c|}{ Sleeping under bed net } \\
\hline Yes & $17(73.9 \%)$ & $17(85.0 \%)$ & \multirow[t]{2}{*}{0.373} \\
\hline No & $6(26.1 \%)$ & $3(15.0 \%)$ & \\
\hline \multicolumn{4}{|c|}{ Sleeping under ITN/LLIN } \\
\hline Yes & $9(39.1 \%)$ & $16(80 \%)$ & \multirow[t]{2}{*}{0.007} \\
\hline No & $14(60.9 \%)$ & $4(20.0 \%)$ & \\
\hline \multicolumn{4}{|c|}{$\begin{array}{l}\text { Wearing long clothes, gloves or using a } \\
\text { scarf }\end{array}$} \\
\hline Yes & $11(47.8 \%)$ & $15(75.0 \%)$ & \multirow[t]{2}{*}{0.069} \\
\hline No & $12(52.2 \%)$ & $5(25.0 \%)$ & \\
\hline \multicolumn{4}{|c|}{ Burning incense or a coil } \\
\hline Yes & $7(30.4 \%)$ & $13(65.0 \%)$ & \multirow[t]{2}{*}{0.023} \\
\hline No & $16(69.6 \%)$ & $7(35.0 \%)$ & \\
\hline \multicolumn{4}{|l|}{ Burning leaves } \\
\hline Yes & $2(8.7 \%)$ & $6(30.0 \%)$ & \multirow[t]{2}{*}{0.073} \\
\hline No & $21(91.3 \%)$ & $14(70.0 \%)$ & \\
\hline \multicolumn{4}{|c|}{ Using insect repellent on the skin } \\
\hline Yes & $1(4.3 \%)$ & $3(15.0 \%)$ & \multirow[t]{2}{*}{0.23} \\
\hline No & $22(95.7 \%)$ & $17(85.0 \%)$ & \\
\hline \multicolumn{4}{|c|}{ Taking medicine to prevent from malaria } \\
\hline Yes & $1(4.3 \%)$ & $2(10.0 \%)$ & \multirow[t]{2}{*}{0.468} \\
\hline No & $22(95.7 \%)$ & $18(90.0 \%)$ & \\
\hline
\end{tabular}

\section{Factors determining health-seeking preferences}

Face-to-face interviews with 14 worksite representatives and 14 village representatives revealed there were 8 determinants which influenced both worksite workers and villagers in seeking health care when 
they had fever: 1). local and traditional belief; 2). easy availability; 3). arrangement by worksites; 4). local recommendation; 5). service cost; 6). accessibility; 7). trust and relationship; and 8). disease severity.

\section{Local and Traditional Belief}

Treatment by traditional means was the most reported initial treatment option for both types of respondents. Treatment by traditional means included taking of traditional or local medicine and herbs by themselves or recommended by their coworkers or villagers, doing traditional practices called Makalaung, an action of piercing fingertips and toe tips with needle, and/or Sar-chit, an action of scratching the skin with sharp object until the skin was red. They strongly believed that such activities could relieve fever. In addition, some sought treatment from shaman due to spiritual and traditional belief. These traditional methods were quite more common among villagers due to local belief. Although the migrant/mobile workers did not have such practices initially, they espoused such practices from residents and later tried to practice these methods by themselves or took assistance from residents whenever they had fever. In that way, traditional practices became commonly used among those communities, and they supposed that medicine and injections they would take would be effective only after receiving such traditional practices.

One village representative answered:

"The skin has to be scrapped with a tin of condensed milk after applying pain relieving ointment. Then, the skin becomes red. It is like opening sweat pores. After that, we take analgesics. Some people take traditional antipyretic medications. We sleep after taking these drugs. When we wake up, we feel lethargic but our symptoms relieve. There is a traditional belief like that." (Village Head from a village in Kyaukme 05)

One village head explained:

"The people who come from Myanmar (plain area) do not believe Makalaung. However, later, they seek treatment from local health providers and receive Makalaung." (Village Representative from a village in Kyaukme 02)

\section{Easy Availability}

Self-medication also served as the popular choice for both villagers and worksite workers owing to easy availability of western and/or traditional medicine at home or nearby drug stores. Self-treatment involved taking medicine themselves or cocktail drugs purchased from nearby drug shops or stores. The medicine they most often used were analgesics (such as Decolgen, paracetamol and Neomixagrip), cocktail unspecified drugs and antimalarial medicine, commonly dialogued as "Artesunate". It was also reported that very few people who had history of malaria-like febrile illness took antimalarial drugs at the time of their febrile illness without any malaria diagnostic test.

One village head mentioned: 
"If I sell drugs here, they buy one tablet (analgesic) for 50 or 100 MMK. The symptoms of some people relieve in this way. Some people who do not get well after the medication go to clinic in the city." (Village Head from a village in Hsipaw 01)

One worksite representative expressed:

"There are some drugs they (the workers) are used to take. For example, we take paracetamol if we have headache or Biogesic if we have cold. Like that." (Owner from an agricultural worksite in Hsipaw 01)

\section{Arrangement by worksites}

In most of the worksites, a medical box with western and traditional medicine for symptomatic relief was provided, which was found to be initially and widely used by worksite workers as an initial source of treatment. Some worksites even appointed staff who was able to administer medicine. However, some staff who administered drugs did not have any medical-related training or certificates. They usually dispensed drugs by their own general knowledge.

One worksite representative shared his experience:

"Mild diseases are headache and fever. We don't usually suffer from fever. If they suffer from loose motion, I administer them Metronidazole. I tell them to take drugs based on my knowledge." (Manager from an agricultural worksite in Kyaukme 04)

Few worksite representatives claimed that their worksite workers seek treatment at social welfare clinic. These clinics offered free-of-charge treatment because of the arrangement by worksites. However, one worksite representative reported that free-of-charge services at social welfare health facility could be available to current workers, but not to their family members.

The worksite representative stated:

"Only people who have employee identity cards seek treatment from places which offer free-of-charge service." (Manager from a farming worksite in Kyaukme 03)

Moreover, as an additional service by worksites, there was a transportation arrangement to seek health care at social welfare health facility, the nearest rural health center or private clinics.

"At the moment, as our workers have motorcycles, they go to health providers even if they suffer from nausea or headache. If they cannot walk there, we send them by our worksite's car. Most importantly, because of the easy transportation, they can easily reach a health center" (Manager from a mining worksite in Lashio 01)

Local Recommendation 
Both worksite and village interviewees mentioned that workers and villagers in some instances directly seek health care at health service providers, such as basic health staff, informal providers, and medical doctors. The word-of-mouth recommendation by neighbors/coworkers determined their choice on health service providers.

"When a person in a village provides treatment for illness, the locals tell the others to go there for treatment. They end up receiving treatment there like that." (Village Representative from a village in Kyaukme 02)

\section{Service Cost}

Both villagers and migrant workers could purchase western or traditional medicine at low cost in nearby drug stores, which encouraged self-medication and made it convenient to take medicine on their own. Hence, they would choose this option first rather than seeking care at health care providers. In addition, the respondents reported that they could receive health care from health care providers by credit or flexible payment, which means that patients could pay service charges later or by the time patients could afford or after seasonal harvesting period. Despite credit payment being available for both types of service receivers, it was more common among villagers.

"If we tell her (informal health provider) that I don't have money now, she just gives us injections with credit payment. Based on the disease condition, she comes to give injection the next day at the time when we need injection. Like that. The cost of the treatment can be paid when the patient gets cured and can work. That becomes traditional behavior of mountainous areas." (Village Head from a village in Kyaukme 05)

\section{Accessibility}

The preference on providers (basic health staff or informal provider) depended on accessibility to nearby service providers and home services provided. It was often reported that most migrants sought care from basic health staff nearby whereas villagers chose a private clinic if their vicinity was closed to the town as most of private clinics located in the town. Moreover, the village representatives reported that there was a community-based health service provider who could provide rapid malaria diagnostic test, antimalarial medicine, and referral service to health center if a patient did not relieve symptoms. However, the representative of one worksite reported such volunteer services.

"It is convenient to seek treatment from a village midwife because we don't have to go to her place. She comes to our houses and gives treatment." (Manager from a farming worksite in Kyaukme 03)

"The informal providers give home visit when they are asked to provide home service. They don't care for financial issue. They just help if they are asked for home visits." (Village Representative from a village in Kyaukme 02) 
"He (a malaria volunteer) provides blood test service. He takes blood from fingertips and gives medication. That all are free of charge." (Village Representative from a village in Hsipaw 04)

\section{Trust and Relationship}

Mutual trust, prior good relationship and friendly nature of health services providers influenced care receivers to choose one of health care providers (either basic health staff or informal providers or medical doctors). The worksite representatives reported that there was no language barrier between workers and the basic health staff because most of the government staff could speak Burmese well. In addition, workers much more preferred basic health staff than informal providers. However, traditional healers or informal providers were more popular among the villagers owing to trust, being friendly, belief in traditional ways of treatment and being able to speak local Shan languages.

A worksite representative praised how the health assistant at her village could cure any diseases.

"We have a health assistant here. Moreover, there are 3-4 nurses. The medical proficiency of the health assistant is good. They can cure mild cases. We don't have to go anywhere. We don't even need to go to the city." (Owner from an agricultural worksite in Hsipaw 01)

One villager shared his experience of language barrier:

"I think the health assistant is from Monywa. Thus, he doesn't know how to speak in Shan language. Most importantly, language. If a person does not know how to speak in local language, it is a little difficult for us to communicate with him. Thus, we rely more on a person who we can communicate freely with." (Village Head from a village in Kyaukme 05)

On the other hand, one worksite representative shared different stories of language barrier:

"As the health providers communicate in local language, we do not have any other choice. As we are Burmese, we are afraid that the treatment given by these providers are not appropriate for us. Thus, we seek treatment from Sayarmalay's clinic, which is a Burmese clinic. We dare not seek treatment from local clinics." (Owner from a construction worksite in Hsipaw 05)

In addition, quality of health services and trust in the medical proficiency and knowledge of medical doctors were the reasons why formal private doctors and basic health staff were approached as both initial and secondary ways of treatment. Moreover, previous good memory of quick recovery and severe disease conditions also encouraged them to prefer formal health care providers.

The village head and worksite representative shared their views on the preference of private doctors.

"They (the villagers) go to the places where there are doctors. They get examined by the doctors. The doctors use stethoscopes. Thus, they know the conditions of the patients (both inside and outside). Therefore, people mostly say that it is more certain to go to places where the doctors give treatment." 
"As the workers come from the central part of Myanmar, they don't believe anyone apart from doctors. Thus, they don't seek treatment from any other providers." (Manager from a mining worksite in Lashio 01)

\section{Disease Severity}

If a patient was not recovered by any initial treatment of mostly traditional methods and self-medications, they usually seek secondary source of health care at the rural health center, private clinics, or public hospital. The basic health staff and private clinics were the most often reported ways after initial selftreatment of either traditional or western means. The reasons for preferring such basic health staff and private clinics were the same as mentioned above, such as trust on quality of services, home visit, friendly nature of staff and flexible payment.

One village head explained:

"If we suffer from headache or cold, we buy drugs from drug stores and take them. If the illness did not relieve after the treatment, we asked Aunty...... (a midwife) to give us an injection. Like that." (Village Head from a village in Hsipaw 02)

Similarly, one worksite representative shared their health seeking practice as follows:

"First, we do Makalaung and then, take traditional medication. We add paracetamol for headache. Then, we go to Sayarma (a basic health staff) to get one or two injections." (Owner from an agricultural worksite in Kutkai 02)

The government hospital was the last option if sick person was not cured by initial formal and nonformal health services at their places. They mentioned that they would choose hospital only at the conditions when they believed symptoms became worsen and hospitals could provide 24-hour service.

One worksite representative shared her thoughts:

"Sometimes, I mostly send my employees to Lashio Hospital for their benefit (if their symptoms don't get better). I don't usually send them to Hsipaw. There are more health providers in Lashio. In addition, it is a township. Lashio is a bigger township than Hsipaw. Therefore, it is more reliable for us." (Owner from an agricultural worksite in Hsipaw 01) 
Table 4

Factors determining health-seeking preferences among worksite workers and villagers

Descriptions

Local and Traditional Belief

Local belief that taking traditional/local medicine and herbs and doing traditional practices (e.g. "Makalaung" - an action of piercing fingertips and toe tips with needle) would certainly relieve fever prior to or together with western medicine. Some also seek treatment from shaman due to spiritual and traditional belief.
Similarities

Traditional belief and local routine health practices influenced both residents and migrants to take such traditional means as the most commonly reported initial treatment option.
Differences

These methods were quite more common among villagers. Despite these methods not being popular among migrants at first, the locals persuaded them to espouse such practices from them.

\section{Easy Availability}

Easy availability of traditional or western medicine at home or nearby drug stores encouraged self-medication and made convenient to take medicine on their own. Selftreatment involved taking medicine themselves or cocktail drugs purchased from nearby drug stores. The medicine they most often used were analgesics (such as Decolgen, paracetamol, Neomixagrip), traditional drugs (e.g. Shan drug power) and cocktail unspecified drugs.
Self-treatment served as the popular choice for both villagers and worksite workers as one of the initial treatment options.

\section{Arrangement by worksites}

Providing a medical box with western and traditional medicine for symptomatic relief at most of the worksites promoted workers to choose as the initial treatment.

Some worksites planned for their workers to seek health services at social welfare health centers without any charges

Also, some worksite owners arranged transportation for their staff to seek health care at the formal health care services
No similarity

In some

No difference
The word-of-mouth recommendation by neighbors determined choice on health service providers, which may be either informal providers, basic health staff, medical doctors or community health providers. instances, workers and villagers directly seek health care at health service providers without taking any prior self-medication.

No difference

\begin{abstract}
All these mentioned services only available at some worksites. From a medical box, the staff who administered drugs did not have any medical-related certificates.
\end{abstract}

No medical box available at village.

\section{Local Recommendation}




\section{Service Cost}

Low cost to purchase medicine on their own

Received treatment from informal providers and basic health staff by credit payment, which means that patients could pay service charges later, by the time patients could afford or after seasonal harvesting period.
Low cost to buy medicine at drug store encouraged self-medication among all locals and workers rather than seeking care at health providers.
Credit payment was more common among villagers despite being available for both.

\section{Accessibility}

Nearby health service providers or drug stores

Home health services by informal providers and basic health staff

Accessible to malaria testing and treatment services via community health service volunteers
Nearby drug stores and home service by informal providers and basic health staff gave an access to health services among locals and migrants
Most migrants sought care from basic health staff nearby.

Some villages had the trained community volunteers who could provide malaria services to villagers, but very few worksites' representatives reported volunteer services

Trust and Relationship

Quality of services, prior good relationships and friendly nature of health services providers influenced care receivers to choose one of health care providers (either basic health staff or informal providers or medical doctors).

Trust on the medical proficiency was one of the determinants in selecting formal health care providers.

No communication barriers
All the mentioned reasons were important for both locals and migrant workers in selecting health service providers.

Both migrants and locals preferred formal health care by medical doctors and basic health staff due to trust on medical proficiency.
Migrant workers chose formal health service providers (medical doctors or basic health staff) who had no language barriers with them whereas locals favored informal providers and local health staff owing to being friendly and able to speak local Shan languages. 
Similarities

Mostly, both

locals and

migrants chose

the formal health

centers or

hospitals for their

secondary source

of health care

\section{Barriers in seeking health care}

Barriers to seeking health care reported in this study were health facility barriers, self-barriers and location barriers.

\section{Health facility barriers}

In terms of health facility barriers, the participants expressed inaccessibility to formal health service facilities, unavailability of diagnostic test, for example, malaria rapid diagnostic test (RDT), and poor communication by health staff in their residency, which led to delay in getting proper treatment among their workers and villagers. They experienced insufficient numbers of government health staff because only one health staff had to take responsibility for seven or eight villages and that health staff had frequent travel to the town for meetings. Some reported that they did not have any testing experience for fever cases and most health providers usually prescribed medicine at first to relieve symptoms and/or referred very ill patients with or without malaria presumptive symptoms directly to hospital. Therefore, they thought testing services for malaria were not available in their region.

Poor communication reportedly happened more frequently in villages than in worksites. Residents mostly could not speak Burmese language well, that made them reluctant to speak out with Burmese health staff. A few village heads complained that most public health staff and hospital staff did not show their hospitality and sometimes scolded them, especially in cases of not being able to buy the necessary medicine they asked for. This often led to misunderstandings between health providers and patients. Such situations of language barriers and unwelcome behavior of formal health staff caused them not to seek care at public health center if the condition was not severe. However, worksite workers encountered language barriers in different way. As most of the mobile and migrant workers were Burmese, they did not understand or speak local Shan language. Therefore, they had trouble in buying drugs or seeking treatment from local traditional healers. Thus, they usually went to the health providers who could speak Burmese language well, mostly the government staff.

One village head shared:

"I think there may be some misunderstandings between some people and doctors and nurses from a hospital because these people don't understand their questions due to language barrier. Sometimes, there 
may be some misunderstandings of the instructions of medical personnel. Therefore, some illness that can be cured within 10 days take about a week to recover." (Village Head from a village in Hsipaw 01)

One worksite representative said:

"As this is an ethnic village, the locals mostly seek treatment from local health providers. As the local health providers are of Shan ethnic group, most Shan get medical attention from them. As we are Burmese, we can only go to Sayarma (a basic health staff) who can explain to us (about our disease condition) properly in Burmese language well. We all go to her if we get hurt from minor worksite injury."

(Owner from a construction worksite in Hsipaw 05)

\section{Self-barriers}

Both village heads and worksite representatives mentioned that their villagers and worksite workers had financial difficulties accessing proper health care. Most workers relied on seasonal jobs and most residents on seasonal farms for their livings. They did not usually save extra money for their health as well as no health coverage by most of the worksite owners. In addition, their daily incomes and health care costs were almost the same at least for one-time health care. Therefore, it was challenging for them to afford both transportation charges and medical fees to seek treatment at the formal health centers or hospitals. They added that it would take time to reach health centers, so they might need to take time off work to seek health care. Most workers in both worksites and villages were daily wage earners, so they lost their daily income if they took time off to seek health care. That was also another reason why the residents and workers had to take a palliative drug at a nearby drug store or self-medication to relieve their symptoms.

"People have financial difficulty. In our villages, we earn money only at the harvesting season of corn. Only once a year! The people who own pineapple plantation earn money twice a year. The people who only plants corn earn money once a year. We only do corn plantation. Nothing else." (Village

\section{Representative from a village in Hsipaw 04)}

"As they are daily wagers, we cannot give them leave like that (for seeking health care). If they fail to work (for a day), we cannot give their daily wage. Besides the daily-wagers, there are also permanent staff like administrative staffs. We give them leave." (Manager from an agricultural worksite in Kyaukme 04)

A few participants reported that most local residents and workers had fear of visiting health service providers, for example, the white coat effect. This intrinsic fear caused them to delay seeking health care at health facilities and is further exacerbated by language barriers between the villagers and medical staff. Having prior negative experience at health centers also prevented both villagers and worksite workers from visiting health staff whereas no prior experience of visiting health facilities exhibited the reluctance of local people to seek treatment at health centers. Furthermore, village heads reported that there were community volunteers received training from government or non-governmental organization, but most villagers did not have trust on them as they think they have less experiences and were in young 
age. Also, they complained that volunteers could provide only rapid diagnostic test for malaria, not other diagnosis, and treatment. Therefore, people rarely visited those volunteers for their general health care.

One village head reckoned:

"As you know, the people from the mountainous regions are afraid of clinics and hospitals. Everyone fears to go to them." (Village Head from a village in Kyaukme 05)

Worksite representative said:

"People are afraid of hospitals as they have no experience in dealing with them. They fear about communication. They have also more or less financial difficulties. Some people might have fear of Sayarma (a health provider) since they had had no experience in dealing with her since their childhood and of injections." (Manager from a farming worksite in Kyaukme 03)

"People don't trust him (a malaria volunteer) as he is kind of inexperienced. He only provides malaria diagnostic tests to check whether a person suffers from malaria. Like that. He only provides blood tests without any treatment. That's why people don't go to and trust him. If people are suspected themselves of suffering from malaria, they come to him for a blood test. Like that. I have never heard that he administers antimalarials." (Village Representative from a village in Kyaukme 02)

Both worksite representatives and village heads reported that most of residents and workers had poor health knowledge due to limited access to health messages and talks. They usually perceived negative attitude towards health education talks too.

Village head said:

"Some people think that they gain nothing from health talks as treatments not given there. In their mind, they don't think that they can gain much knowledge if they really listen to this knowledge and keep them in mind. Some people have fair amount of knowledge they should know if we really ask them." (Village Head from a village in Hsipaw 02)

One worksite representative explained that low health knowledge of his workers led them to do selfadministration of drugs:

"I: Why do you buy drugs from outside drugstores? Which difficulty do you have?

R: Some people don't even know about their health condition, Sayarma. They say that they suffer from fever with chills and rigors but they don't know that it is the sign of malaria." (Owner from a construction worksite in Hsipaw 05)

\section{Location Barriers}


As the interviewed worksites and villages were mostly located near or within the forest, transportation difficulties to reach health care centers were commonly reported for them residing in hard-to-reach vicinities. They normally needed multiple modes of transport to reach the nearest health center in their residency. In the unexpected and unpleasant weather conditions, roads were mostly damaged, where it was hard to transport patients to health centers. Even in dry season, they could not reach health centers at night. Such situations of devastated roads in their area still hindered them from reaching health facilities. A few village heads mentioned that insecure conditions within their residency were also one of their barriers in seeking proper treatment at health care facility. During armed conflict period or whenever there were armed groups on the way to health facility, village authorities must contact both sides of armed conflict groups and ask their permission to use a road to health facility. Even in the cases of emergency conditions that happened at night, they had to wait until morning to send patients to the nearest health facility. Therefore, insecurity was the main barrier in this community, which delayed them in seeking proper health care at health facilities.

"In our village, we have only ten households. The insurgent groups come to a village regardless of the number of households. When they come to a village, the village head or administrator know the leaders of these groups. We have their contact numbers given by these groups. If we encounter difficulties (health related ones), the village head or administrator can make a call to them. For us who live in a hilly region, an armed conflict occurred in our village, Top-San." (Village Head from a village in Kyaukme 05)

One worksite representative cited that worksite owners usually restricted their workers going beyond their worksite compound especially at nighttime due to their work nature and insecurity issue nearby. If workers went outside a worksite compound in their own mind, the worksite authorities could not guarantee their safety.

He said:

"R: They (workers) go to outside at night. Frankly speaking, due to the current situation, work nature and environmental condition, we restrict them going outside. They take responsibility of their safety if they live within the worksite compound. But I don't allow them to go outside. If anything happens when they go outside, I am not responsible in that case. (Manager from an agricultural worksite in Kyaukme 04) 
Table 5

Barriers in seeking health care

\begin{tabular}{|lll|}
\hline Barriers & Descriptions & Villages \\
\cline { 2 - 3 } & Worksites & \\
$\begin{array}{l}\text { Health facility } \\
\text { Barriers }\end{array}$ & & \\
$\begin{array}{l}\text { Inaccessible to } \\
\text { formal health } \\
\text { service } \\
\text { facilities }\end{array}$ & $\begin{array}{l}\text { Insufficient numbers of government health } \\
\text { staff and worksite locating in hard-to-reach } \\
\text { area }\end{array}$ & $\begin{array}{l}\text { Insufficient numbers of } \\
\text { government health staff }\end{array}$ \\
$\begin{array}{l}\text { Unavailability } \\
\text { of diagnostic } \\
\text { test }\end{array}$ & No experience of getting diagnostic services & $\begin{array}{l}\text { Same as mentioned in } \\
\text { worksites. }\end{array}$ \\
$\begin{array}{c}\text { Poor } \\
\text { communication } \\
\text { by health staff }\end{array}$ & $\begin{array}{l}\text { No language barriers with government health } \\
\text { staff. }\end{array}$ & $\begin{array}{l}\text { Local residents have } \\
\text { language barriers in } \\
\text { communicating with } \\
\text { Burmese health staff, which } \\
\text { often leads to } \\
\text { misunderstanding between } \\
\text { health providers and } \\
\text { patients. }\end{array}$ \\
\hline
\end{tabular}

Self-Barriers

Financial difficulties and work nature
Mostly were seasonal workers and daily-based ones, with no spare money to be able to afford both transportation and medical charges at formal health care facilities. Daily-based workers were often reluctant to take a leave from work for their income, so mostly relied on self-medication or nearby drug shop.

Fear and trust

Fear of visiting health service providers and prior no experience at health care facility, and prior negative experience causes them to delay seeking care at formal health facility.
Same as mentioned in worksites.
Fear of visiting health service providers, language barriers, no prior experience at health care facility, and prior negative experience caused them to delay seeking care at formal health facility.

Moreover, villagers did not have trust on community volunteers trained by government and /or nongovernmental organizations.

Same as mentioned in worksites.
Limited health Limited access to health education activities knowledge and negative perceptions towards health education talks. 


\begin{tabular}{|c|c|c|}
\hline \multirow[t]{2}{*}{ Barriers } & \multicolumn{2}{|l|}{ Descriptions } \\
\hline & Worksites & Villages \\
\hline $\begin{array}{l}\text { Hard-to-reach } \\
\text { area }\end{array}$ & $\begin{array}{l}\text { Mostly located in hard-to-reach area, } \\
\text { devastated road condition and often needed } \\
\text { multiple modes of transport to reach health } \\
\text { centers. }\end{array}$ & $\begin{array}{l}\text { Same as mentioned in } \\
\text { worksites }\end{array}$ \\
\hline \multirow{2}{*}{$\begin{array}{l}\text { Insecurity by } \\
\text { frequent armed } \\
\text { conflicts }\end{array}$} & Insecure on the way to health facility. & $\begin{array}{l}\text { Insecure on the way to } \\
\text { health facility. }\end{array}$ \\
\hline & $\begin{array}{l}\text { Restricted workers not to go beyond the } \\
\text { worksite compound due to frequent armed } \\
\text { conflicts and worksite nature. }\end{array}$ & $\begin{array}{l}\text { Village authorities must ask } \\
\text { permission from armed } \\
\text { conflict groups to use the } \\
\text { way to health facility. }\end{array}$ \\
\hline
\end{tabular}

\section{Discussion}

In this study, considerably larger number of worksites reported that their workers did not use LLIN compared to the villagers of nearby villages despite both populations resided in the same malaria endemic area of Northern Shan State. That could be explained by insufficient LLINs in the worksites, barriers on LLIN distributions to these worksites in the study areas and poor knowledge and bad attitudes of workers to LLIN use and its benefits against malaria (26). Self-treatment was a popular first treatment option in both village and worksite populations. Despite the similarity, these two populations were different in that while the villagers were said to be relied on self-treatment with traditional method and leftover drugs at home, the workers were reported to mostly take drugs from medical box provided by the worksites. Moreover, the villagers were said to rely more on informal providers whereas the worksite representatives said that the workers preferred formal providers like basic health staff. Furthermore, transport arrangement and social welfare health services were available only for workers. Villagers and workers alike went to government hospital only for severe disease condition. Insufficient manpower for formal health service, limited access to malarial diagnostic test, communication difficulty with service providers, fear, transportation difficulty and insecure living conditions due to frequent armed conflicts were the most reported barriers in seeking health care for both workers and villagers. While poor communication with health providers happened more frequently in villagers, inability to seek care due to worksites location in hard-to-reach areas and transportation barriers were frequently found among workers. These findings point to the need for programs to fully understand the root causes of limited access to health care. The differences and similarities between these two populations can be leveraged to deliver effective malaria control interventions.

People in the study areas were found to have limited access to quality treatment and diagnostic tests for malaria. Most of them did not know where they could receive RDT for malaria diagnosis and most health providers gave them treatment without any test, leading them to think that RDT testing was not available in their regions and took medication or directly went to health providers. From this situation, it could be assumed that the usage of RDT was low in the study areas. The low level of RDT testing had been 
previously discovered in the study of ethnic minority resided in China-Myanmar Border (16). Moreover, mobile and migrant workers used ITN/LLIN relatively less than their village counterparts (39\% of worksites and $80 \%$ of villages). The finding about mobile and migrant population was consistent with previous studies in Tanitharyi Region (2) and Thailand (27). In the study in Tanitharyi Region, only $50 \%$ of the mobile and migrant workers slept under ITN/LLIN (2). Similarly, in Thailand, $25.8 \%$ of malaria affected households in villages where majority of rubber plantation workers lived slept under ITN/LLIN (27). In contrast, the household study about ethnic groups in Northern Myanmar found that $73.9 \%$ of households owned ITN/LLIN (5). The findings highlighted health inequality in both villagers and mobile and migrant workers residing in the forest-related areas of the Northern Shan State, in terms of assessing quality malaria diagnosis and treatment, and migrant populations were more adversely affected with lesser access to effective malaria prevention measure. However, there were study methodological differences between the previous studies and this current one in the sense that the former were household surveys while the latter did interviews with representatives of villages and worksites.

The possible explanations for these unequal malaria service accesses were unsafe and unsecure residency for both villagers and mobile migrants. Frequent armed conflicts in Northern Shan State made villagers and workers difficult to go to formal health workers in accessing required health services as necessary (28). In addition, almost all mobile migrant workers and villagers were daily-wage earners, who could be unpaid for their absent days. This might be another reason why they were reluctant to go to formal health providers by taking unpaid leave. The worksites had more barriers to access to health services and could be hardly reached by health workers because of legal status of worksites and nature of work. It was reported that there might be either legal and illegal worksites or workers in the border areas, and such illegal status hampered them from connecting with formal health networks due to fear of punishment (29). Moreover, being absence of community health workers in most worksites consequently prevents workers from receiving timely malaria diagnosis and treatment. Hence, National Malaria Control Program (NMCP) and malaria partners should take account of these aforementioned possible reasons for unequal malaria access among mobile and migrant worker and village populations, and they should pay special attention to ITN/LLIN distribution among mobile migrant population.

The other reason for not accessing proper malaria care was self-treatment, which was the mostly used treatment options among villagers and mobile and migrant workers. The former relied more on treating themselves with traditional methods and leftover drugs at home while the latter used medications from medical box provided by their worksites. Both relied on drugs bought from drugstores near their home. The action of villagers' self-treatment by taking 'left-over' drugs at home or drugs from drugstores as initial treatment were reported in many previous studies $(11,30-33)$. The reasons behind both the villagers and worksite workers practicing self-medication were due to low cost, easy drug availability, unwillingness to take leave from work and mild disease severity. Long travel distance to health providers and unsafe environmental conditions also added to their reluctance to go to formal health facilities. A previous study in Bago Region found that mobile and migrant workers could easily access medications at small shops or drugstores and thus, did self-treatment with these drugs (7). 
In addition to self-treatment, the villagers mostly relied on informal providers and sometimes, traditional healers while the workers preferred formal providers like basic health staffs. They went to these providers either directly or after doing self-treatment or traditional methods at home. The language barrier was the commonly reported reason behind both of their preferences. Both villagers and workers preferred going to health providers who could communicate well in their languages, Shan and Burmese languages respectively. Other reasons behind the villagers and workers' choice of informal providers and traditional healers were home service availability, easy accessibility, having trust and good relationship with the providers, word-of-mouth recommendation by neighbors and credit or flexible payment while both sought treatment from basic health staffs for the same reasons. Moreover, the worksite workers received treatment from basic health staffs because of transportation arranged by the worksites. Similarly, the previous study in the Bago Region found out that easy accessibility, trust and good relations with the providers caused migrant workers to seek health care from the informal sector (7).

NMCP concentrates on expanding community-based malaria case management with the help of community health workers trained by the government and non-governmental organizations $(29,34)$. It found that malaria case finding through community workers in Myanmar was the most efficient approach with minimal resources required (35). However, this study pointed out the gap in health coverage by community health workers amongst a key vulnerable population. Although there were community health workers in some villages, most worksites did not have these providers for timely malaria diagnostic test and treatment. From the words of some village heads, the villagers had less trust on community health workers and did not rely on them because the providers were relatively young compared to other providers and they could provide only malaria diagnostic test and treatment. However, some worksite representatives requested to send the community health worker for malaria services and to train one of their workers to be ready for malaria case finding and early treatment. Therefore, NMCP and partner organizations should consider recruiting community-trusted volunteers in worksites or within the vicinity of worksites, and equipping them with malaria comorbidity and skills.

With regards to barriers in seeking treatment, both worksite workers and villagers were unable to access formal health services and diagnostic tests, and experienced communication gaps with health providers. Being daily wagers, both had financial difficulties and were reluctant to take leave to receive health care for their illness. Moreover, they both had limited health knowledge, fear or trust problems to visit formal health facilities. Being resided in hard-to-reach areas with poor transportation and insecure conditions, and frequent armed conflicts had worsened the situation to seek treatment outsides for malaria. Our study is consistent with from recent local studies conducted among mobile migrant workers in malaria elimination areas and among Wa ethnic minority in Myanmar $(2,7,16)$. They reported the remoteness of their worksites, far distance from a health facility, transportation constraints, security concerns, unsuitable open hours of clinics, and social distance hindering them from accessing to formal health services $(2,7,16)$. Language barrier was also a non-negligible issue in seeking health care as the majority of the migrant populations understood Myanmar language while the local villagers speak their ethnic language, which was proved to impede their understanding of health message from their providers (2, 10). In addition to these limitations, financial income and lack of ready cash were also the reported 
barriers associated with treatment seeking in both rural ethnic Myanmar (16) and Cambodia (36). Hence, our study was able to document a wide range of individual and contextual constraints among both mobile migrants and rural ethnic populations, which may hamper their health seeking practices at formal health care and likely increase potential risk of malaria transmission in these malaria at-risk areas. Therefore, local health authorities and non-profit health organizations should seek to increase trust and overcome geographic and language barriers that hinder access to health services in order achieve the National Malaria Elimination targets in Myanmar (29).

This study is limited to inference drawn from quantitative and qualitative insights across a small number of respondents in the targeted hard-to-reach and malaria at-risk areas, so that it cannot be nationally representative. In addition, since discussions were made only among key stakeholders of the study worksites and villages, not individual workers and villagers, the findings were not able to generalize to individual levels, and there might be other individual-level factors or barriers that may not be observed in this study. However, key informant interviews have several advantages to collect needed information, ideas, and insights that cannot be obtained with other methods since our data came directly from more knowledgeable people, who may offer confidential information that would not be revealed in other settings. They may also tell of issues, local happenings, or conditions that explained overall problems. In addition, the draft interview guide was subsequently improved after each interview to explore new ideas and issues that had not been anticipated in planning this study but that were relevant to the study purpose. As an additional strength, it was, to our knowledge, the first study that could highlight the considerable differences and gaps in malaria preventive measure and health seeking behaviors between site workers and residents despite living in the same geographical areas.

\section{Conclusion}

The National Malaria Control Program, Myanmar, aims to ensure equitable and universal accesses to effective preventive and curative measures to all 'malaria at-risk populations', given a priority of the most vulnerable and hard-to-reach mobile and ethnic populations living or spending time in remote forested areas (29). However, our study highlights the gaps in access to LLIN and malaria diagnosis and treatment among mobile migrant populations and ethnic minority people residing in Northern Shan state, which is the malaria-at-risk areas of the Eastern Myanmar close to the Chinese border. Low to LLIN use was reported among the worksites than the villages in the same geographical regions. Although selfmedication was the primary preference for seeking care related to any febrile illness for both communities, the two study groups had different motivations for this care seeking practices. Programs seeking to implement malaria control interventions and facilitate malaria elimination need to recognize such similarities and differences, to strengthen and effectively design and target malaria intervention approaches in those malaria-at-risk areas.

\section{List Of Abbreviations}

CsPro Census and Survey Processing System 
GMS the Greater Mekong Subregion

ITN Insecticide treated nets

LLIN Long-lasting insecticidal nets

NMCP National Malaria Control Program

PSI Population Services International

RDT Rapid diagnostic test

\section{Declarations}

\section{Ethics approval and consent to participate}

The Ethics Review Committee on Medical Research Involving Human Subjects, Department of Medical Research, Ministry of Health and Sports, Myanmar (Ethics/DMR/2019/007) and the PSI Research Ethics Board (\#21.2018) approved this study, and all the study participants were asked for the written informed consent form.

\section{Consent for publication}

Not applicable

\section{Availability of data and materials}

Not applicable

\section{Competing interests}

The authors declare that they have no competing interests.

\section{Funding}

No funding was available for this manuscript.

\section{Authors' contributions}

YKA, MMT and STT participated in developing the study concept, while YKA led the data collection team. YKA and SSZ were included in the data analysis and all authors contributed in manuscript writing. All authors read the final manuscript and provided the comments.

\section{Acknowledgements}


We appreciatively acknowledge all contributions to this study, including the study participants and the support of Myanmar National Malaria Control Program, Regional Health Department in the Northern Shan State, and all local implementing partners. All authors have solely responsibilities for the contents of this publication although this study was conducted under the PSI/Myanmar's Malaria project funded by Regional Arteminisin-resistance Initiative (RAI) and the Greater Mekong Subregion Elimination of Malaria through Surveillance (GEMS) program funded by the Bill and Melinda Gates Foundation.

\section{References}

1. World Malaria Report 2017. Geneva: World Health Organization; 2017. Report No.: 978-92-4-1565523.

2. Wai KT, Kyaw MP, Oo T, Zaw P, Nyunt MH, Thida M, et al. Spatial distribution, work patterns, and perception towards malaria interventions among temporary mobile/migrant workers in artemisinin resistance containment zone. BMC Public Health. 2014;14:463.

3. Cui L, Yan G, Sattabongkot J, Cao Y, Chen B, Chen X, et al. Malaria in the Greater Mekong Subregion: heterogeneity and complexity. Acta Trop. 2012;121(3):227-39.

4. Help prevent malaria [press release]. Myanmar: World Health Organization2018.

5. Wang RB, Dong JQ, Xia ZG, Cai T, Zhang QF, Zhang Y, et al. Lessons on malaria control in the ethnic minority regions in Northern Myanmar along the China border, 2007-2014. Infect Dis Poverty. 2016;5(1):95.

6. Bui HM, Clements AC, Nguyen QT, Nguyen MH, Le XH, Hay SI, et al. Social and environmental determinants of malaria in space and time in Viet Nam. Int J Parasitol. 2011;41(1):109-16.

7. Win AYN, Maung TM, Wai KT, Oo T, Thi A, Tipmontree R, et al. Understanding malaria treatmentseeking preferences within the public sector amongst mobile/migrant workers in a malaria elimination scenario: a mixed-methods study. Malar J. 2017;16(1):462.

8. Hlaing T, Wai KT, Oo T, Sint N, Min T, Myar S, et al. Mobility dynamics of migrant workers and their socio-behavioral parameters related to malaria in Tier II, Artemisinin Resistance Containment Zone, Myanmar. BMC Public Health. 2015;15(1):886.

9. Karyana M, Devine A, Kenangalem E, Burdarm L, Poespoprodjo JR, Vemuri R, et al. Treatment-seeking behaviour and associated costs for malaria in Papua, Indonesia. Malar J. 2016;15(1):536.

10. Workshop to Consolidate Lessons Learned on BCC and Mobile Migrant Populations in the Strategy to Contain Artemisinin Resistant Malaria Meeting Report. Lao PDR: Malaria Consortium, World Health Organization; 2011 5-7 July 2011.

11. McCombie SC. Treatment seeking for malaria: a review of recent research. Soc Sci Med. 1996;43(6):933-45.

12. Williams HA, Jones $\mathrm{CO}$. A critical review of behavioral issues related to malaria control in subSaharan Africa: what contributions have social scientists made? Soc Sci Med. 2004;59(3):501-23. 
13. ACT watch Group and PSI/Cambodia. Household Survey Report (Endline). Kingdom of Cambodia: Population Services International; 2011.

14. Aye SS, Nishino Y, Soe K, Zaw KK, Oo YTN, Han WW, et al. Role of private sector in Myanmar's health care system: Implications for health sector reform. 2013.

15. The 2014 Myanmar Population and Housing Census. In: Department of Population MoL, Immigration and Population, editor. Nay Pyi Taw2014. p. 1-103.

16. Xu JW, Xu QZ, Liu H, Zeng YR. Malaria treatment-seeking behaviour and related factors of Wa ethnic minority in Myanmar: a cross-sectional study. Malar J. 2012;11(December 2009):417.

17. Bennett A, Avancena ALV, Wegbreit J, Cotter C, Roberts K, Gosling R. Engaging the private sector in malaria surveillance: a review of strategies and recommendations for elimination settings. Malar $\mathrm{J}$. 2017;16(1):252.

18. Hu J, Podhisita C. Differential Utilization of Health Care Services among Ethnic Groups on the Thailand-Myanmar Border : A Case Study of Kanchanaburi Province, Thailand. Journal of Population and Social Studies. 2008;17(1):115-34.

19. Wang RB, Zhang J, Zhang QF. Malaria baseline survey in four special regions of northern Myanmar near China: a cross-sectional study. Malar J. 2014;13(1):302.

20. Township Profile _ Lashio Myanmar: General Administration Department, Ministry of Home Affairs.; 2017 [Available from: http://themimu.info/township-profiles.

21. Township Profile_Kutkai Myanmar: General Administration Department, Ministry of Home Affairs.; 2017 [Available from: http://themimu.info/township-profiles.

22. Township Profile_ Kyaukme Myanmar: General Administration Department, Ministry of Home Affairs.; 2017 [Available from: http://themimu.info/township-profiles.

23. Township Profile_Hsipaw Myanmar: General Administration Department, Ministry of Home Affairs.; 2017 [Available from: http://themimu.info/township-profiles.

24. World Health Organization. Regional Office for South-East Asia. Mobile and migrant populations and malaria information systems. World Health Organization; 2015.

25. StataCorp. Stata Statistical Software: Release 14. College Station, TX: StataCorp LP. 2015.

26. Linn SY, Maung TM, Tripathy JP, Shewade HD, Oo SM, Linn Z, et al. Barriers in distribution, ownership and utilization of insecticide-treated mosquito nets among migrant population in Myanmar, 2016: a mixed methods study. Malar J. 2019;18(1):172.

27. Satitvipawee P, Wongkhang W, Pattanasin S, Hoithong P, Bhumiratana A. Predictors of malariaassociation with rubber plantations in Thailand. BMC Public Health. 2012;12(1):1115.

28. Humanitarian Needs Overview Myanmar: United Nations Office for the Coordination of Humanitarian Affairs; 2019 [Available from: https://reliefweb.int/report/myanmar/myanmar-humanitarian-needsoverview-2020-december-2019.

29. National strategic plan: Intensifying malaria control and accelerating progress towards malaria elimination (2016-2020). Myanmar: Department of Public Health, Ministry of Health and Sports, The 
Republic of the Union of Myanmar; 2016.

30. Sonkong K, Chaiklieng S, Neave P, Suggaravetsiri P. Factors affecting delay in seeking treatment among malaria patients along Thailand-Myanmar border in Tak Province, Thailand. Malar J. 2015;14(1):3.

31. Chaturvedi HK, Mahanta J, Pandey A. Treatment-seeking for febrile illness in north-east India: an epidemiological study in the malaria endemic zone. Malar J. 2009;8(1):301.

32. Nyamongo IK. Health care switching behaviour of malaria patients in a Kenyan rural community. Soc Sci Med. 2002;54(3):377-86.

33. Simsek Z, Kurcer MA. Malaria: knowledge and behaviour in an endemic rural area of Turkey. Public Health. 2005;119(3):202-8.

34. Community based health worker policy. Myanmar: Ministry of Health and Sports; 2020.

35. Kheang ST, Lin MA, Lwin S, Naing YH, Yarzar P, Kak N, et al. Malaria Case Detection Among Mobile Populations and Migrant Workers in Myanmar: Comparison of 3 Service Delivery Approaches. Glob Health Sci Pract. 2018;6(2):384-9.

36. Verschuere J, Decroo T, Lim D, Kindermans JM, Nguon C, Huy R, et al. Local constraints to access appropriate malaria treatment in the context of parasite resistance in Cambodia: a qualitative study. Malar J. 2017;16(1):81.

\section{Figures}



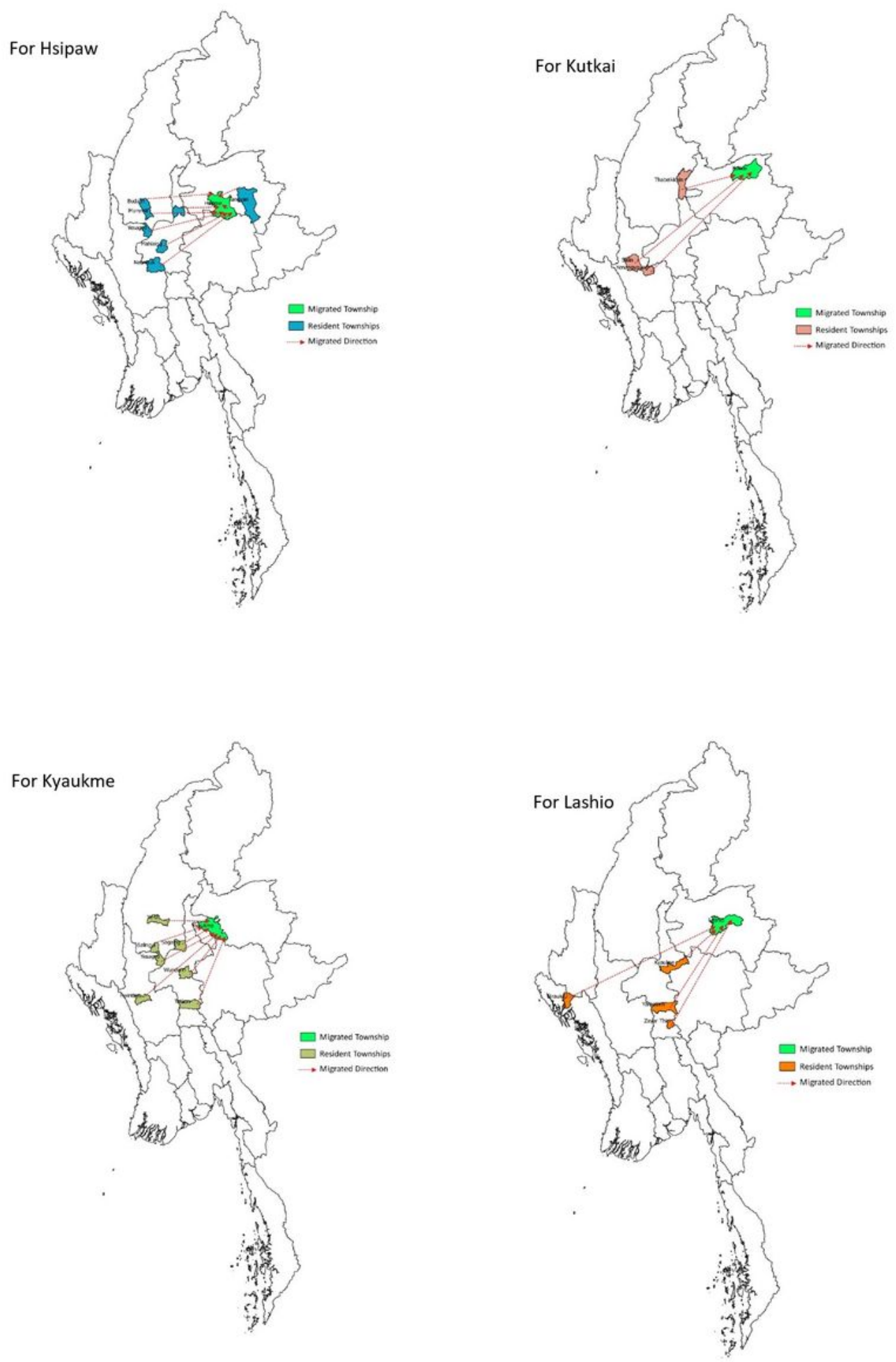

\section{Figure 1}

Maps showing the internal migrations from resident townships to migrated townships 